\title{
Low risk of solid tumors in persons with Down syndrome
}

\author{
Henrik Hasle, MD, PhD ${ }^{1}$, Jan M. Friedman, MD, PhD², Jørgen H. Olsen, MD, DMSc ${ }^{3}$ and \\ Sonja A. Rasmussen, MD, MS ${ }^{4}$
}

Purpose: The aim of this study was to investigate cancer incidence in a large cohort of persons with Down syndrome.

Methods: Down syndrome was identified from the Danish Cytogenetic Register. Cancer occurrence was identified by linkage to the Danish Cancer Registry. Standardized incidence ratios (SIRs) and 95\% confidence intervals (CIs) were calculated based on observed and expected numbers from rates for all Danish residents. The cohort consisted of 3,530 persons with Down syndrome contributing 89,570 person-years at risk.

Results: Acute leukemia risk was highest from 1-4 years of age and remained elevated until age 30 . The overall risk of solid tumors was decreased (SIR 0.45; 95\% CI 0.34-0.59), especially in persons
50 years or older (SIR 0.27 ; $95 \%$ CI $0.16-0.43$ ). We found a significantly lower risk of lung cancer (SIR 0.10 ; $95 \%$ CI $0.00-0.56$ ), breast cancer (SIR 0.16; 95\% CI 0.03-0.47), and cervical cancer (SIR 0.0; $95 \%$ CI $0.00-0.77$ ). Testicular cancer was the only solid tumor with an increased SIR (2.9; 95\% CI 1.6-4.8).

Conclusions: The risk of all major groups of solid tumors was decreased, except testicular cancer. Altered screening strategies should be considered for persons with Down syndrome. This unusual pattern of cancer occurrence may help understanding carcinogenesis in the general population.

Genet Med advance online publication 31 March 2016

Key Words: cancer; Down syndrome; tumor-suppressor genes

\section{INTRODUCTION}

Down syndrome is the most common chromosome abnormality in humans, occurring in about 1 in 800 live births. ${ }^{1}$ Down syndrome is associated with a number of characteristic dysmorphic features and congenital or acquired medical problems. ${ }^{2}$ The pattern of cancer during childhood is unique: leukemias constitute more than $95 \%$ of cancers among children with Down syndrome, compared with about $35 \%$ of cancers among children in the general population. ${ }^{3}$ The survival of individuals with Down syndrome has increased in recent decades (owing mainly to improved management of congenital heart defects), resulting in large numbers of adults with Down syndrome. ${ }^{4}$ There is a need for studies of health issues in this growing population. Previous studies have suggested a lower incidence of solid tumors in adults with Down syndrome, but the results have been limited by the inclusion of a relatively small proportion of older individuals..$^{5-8}$ We compared the frequency of cancer in a large, unselected cohort of persons with cytogenetically diagnosed Down syndrome, including almost 7,000 person-years of observation over 50 years of age, with the frequency in the Danish general population.

\section{Study protocol}

\section{MATERIAL AND METHODS}

This was a registry-based follow-up study of persons with Down syndrome in Denmark. The cohort was identified from the Danish Cytogenetic Register and linked to the Danish Cancer Registry. Data linkage was based on the personal identification number assigned to each resident either in April 1968 or thereafter at the time of birth or arrival in Denmark. The personal identification number is unique to each resident and allows complete follow-up in the national civil status (including death, emigration, and immigration) and health-related registries. This study was approved by the Danish Data Protection Agency.

\section{Study cohort}

The Danish Cytogenetic Register was founded in 1968 with the aim of collecting information on chromosomal abnormalities in Denmark. The register is based on reports from all cytogenetic laboratories throughout the country and is believed to provide virtually complete ascertainment of constitutional chromosomal abnormalities diagnosed in Denmark since 1961. ${ }^{9}$ By December 2007, the Cytogenetic Register contained information on 3,551 persons with a postnatal cytogenetic diagnosis of Down syndrome and a verified personal identification number and residence in Denmark at the time of the cytogenetic study. A karyotype derived from peripheral blood was available from all persons. Cytogenetic diagnoses from the 1960s and 1970s reported as trisomy G were accepted as trisomy 21. People studied with only fluorescence in situ hybridization analysis were

${ }^{1}$ Department of Pediatrics, Aarhus University Hospital, Aarhus, Denmark; ${ }^{2}$ Department of Medical Genetics, University of British Columbia, Vancouver, Canada; ${ }^{3}$ Danish Cancer Society Research Centre, Danish Cancer Society, Copenhagen, Denmark; ${ }^{4}$ Centers for Disease Control and Prevention, Atlanta, Georgia, USA. Correspondence: Henrik Hasle (hasle@dadlnet.dk)

Submitted 11 November 2015; accepted 22 January 2016; advance online publication 31 March 2016. doi:10.1038/gim.2016.23 
not included. All reported karyotypes were reviewed by three authors (S.A.R., J.M.F., and H.H.), and additional data from the reporting cytogenetic laboratory were requested when necessary. After review, five persons were reclassified as not having trisomy 21 and were excluded from the study. People with cytogenetic abnormalities in addition to trisomy 21 were also excluded: XYY $(n=1), \mathrm{XXY}(n=2), \mathrm{XXX}(n=3)$, translocations $(n=7)$, inversions $(n=2)$, and deletion $(n=1)$.

\section{Cancer follow-up}

Cancer occurrence was identified by linkage to the Danish Cancer Registry, which has received notifications of malignant diseases from all clinical and pathological departments in the country since 1943. Notifications to the registry are supplemented by examination of all death certificates for cancer diagnoses. The registry provides practically complete coverage of the occurrence of cancer in Denmark. ${ }^{10}$

Only cancers occurring after the introduction of the personal identification number on 1 April 1968 were selected from the Danish Cancer Registry. Person-years at risk were counted from 1 April 1968, or the date of birth for those born later, until date of death, emigration, or 31 December 2012, whichever occurred first. All cancers were classified according to the International Classification of Diseases, 10th Revision.

\section{Statistical analysis}

The cohort members were followed from birth (or 1 April 1968 for persons born before that date) until time of death, emigration, or the end of follow-up (31 December 2012), whichever came first. Information on emigration was obtained from the Civil Registration System.

The numbers of cancer cases in the study cohort were compared with the expected numbers calculated from rates for all Danish inhabitants specific for sex, 5-year age group, and calendar period. The standardized incidence ratio (SIR) was calculated as the ratio of the observed to the expected incidence. Statistical evaluation was based on the calculation of $95 \%$ confidence intervals (CIs) on the assumption that the observed numbers of cases followed a Poisson distribution. If the CI excluded 1, the SIR was considered to be significantly different from expected.

Lifetime cumulative rates of solid tumors and leukemias were calculated in 5-year age groups for the Down syndrome cohort and the general population.

\section{RESULTS}

The final cohort consisted of 3,530 persons with Down syndrome (1,928 males and 1,602 females) born between 1878 and 2007. Based on karyotype, they were classified as standard trisomy 21 ( $n=3,272 ; 92.7 \%)$, Robertsonian translocations ( $n=$ $144 ; 4.1 \%$ ), or mosaicism (mixture of cells with normal karyotype and trisomy 21$)(n=114 ; 3.2 \%)$. The cohort contributed 89,570 person-years at risk with 48,136 years of risk among
Table 1. Cytogenetic groups, year of birth, and personyears at risk by sex

\begin{tabular}{|c|c|c|c|}
\hline & $\begin{array}{c}\text { Male } \\
(n=1,928 ; \\
55 \%)\end{array}$ & $\begin{array}{c}\begin{array}{c}\text { Female } \\
(n=1,602 ; \\
45 \%)\end{array} \\
\end{array}$ & $\begin{array}{c}\text { Total } \\
(n=3,530)\end{array}$ \\
\hline \multicolumn{4}{|l|}{ Cytogenetic groups } \\
\hline Standard trisomy 2 & $803(93.5 \%)$ & $1,469(91.7 \%)$ & $3,272(92.7 \%)$ \\
\hline Mosaicism & $48(2.4 \%)$ & $66(4.1 \%)$ & $114(3.2 \%)$ \\
\hline $\begin{array}{l}\text { Robertsonian } \\
\text { translocations }\end{array}$ & $77(4.0 \%)$ & $67(4.2 \%)$ & $144(4.1 \%)$ \\
\hline \multicolumn{4}{|l|}{ Year of birth } \\
\hline Before 1920 & 14 & 29 & 43 \\
\hline 1920-1939 & 106 & 124 & 230 \\
\hline 1940-1959 & 316 & 242 & 558 \\
\hline 1960-1979 & 663 & 548 & 1,211 \\
\hline 1980-1999 & 645 & 491 & 1,136 \\
\hline 2000-2007 & 184 & 168 & 352 \\
\hline \multicolumn{4}{|c|}{ Person-years at risk, by age } \\
\hline Total & 48,747 & 40,823 & 89,570 \\
\hline $0-4$ & - & - & 10,410 \\
\hline $5-9$ & - & - & 10,857 \\
\hline $10-14$ & - & - & 10,478 \\
\hline $15-19$ & - & - & 9,690 \\
\hline $20-24$ & - & - & 8,913 \\
\hline $25-29$ & - & - & 8,117 \\
\hline $30-34$ & - & - & 7,426 \\
\hline $35-39$ & - & - & 6,594 \\
\hline $40-44$ & - & - & 5,608 \\
\hline $45-49$ & - & - & 4,521 \\
\hline $50-54$ & - & - & 3,270 \\
\hline $55-59$ & - & - & 2,098 \\
\hline$\geq 60$ & - & - & 1,589 \\
\hline
\end{tabular}

persons 20 years of age or older and 6,957 years at risk among persons 50 years of age or older (Table 1 ).

The overall risk of cancer was not significantly different from what was expected (SIR 0.84; 95\% CI 0.70-1.02) (Table 2). Lymphomas and leukemias were more frequent than expected among persons with Down syndrome (SIR 5.5; 95\% CI 4.2-7.1), and solid tumors were less frequent than expected (SIR 0.45; 95\% CI 0.34-0.59). The risk of all major groups of malignant solid tumors was decreased, with the exception of testicular cancer (SIR 2.9; 95\% CI 1.6-4.8). Most notable were the very low risk of lung cancer (SIR 0.10; 95\% CI 0.00-0.56), skin cancer (SIR 0.24; 95\% CI 0.10-0.48), cervical cancer (SIR $0.0 ; 95 \%$ CI $0.00-0.77$ ), and female breast cancer (SIR 0.16; 95\% CI 0.03-0.47). Only 3 cases of breast cancer (carcinomas at age 31,47 , and 55 years) were observed versus 18.6 cases expected.

Testicular cancer was diagnosed in 14 males with Down syndrome (median age 35 years, range 18-45 years). Histology of the testicular tumors showed seminoma $(n=9)$, teratocarcinoma $(n=1)$, embryonal carcinoma $(n=3)$, and mixed 
Table 2. Standardized incidence ratios and observed and expected numbers by cancer site among 3,530 persons with Down syndrome

\begin{tabular}{|c|c|c|c|c|}
\hline Site (ICD-10 codes) & Observed (n) & Expected $(n)$ & SIR & $95 \% \mathrm{Cl}$ \\
\hline All sites (COO-C 14) & 113 & 134 & 0.84 & $0.70-1.02$ \\
\hline Buccal cavity (COO-C14) & 0 & 3.20 & 0.0 & $0.00-1.15$ \\
\hline Digestive system (C15-C26) & 8 & 15.3 & 0.52 & $0.22-1.03$ \\
\hline Esophagus (C15) & 1 & 0.99 & 1.01 & $0.01-5.60$ \\
\hline Stomach (C 16) & 3 & 1.81 & 1.65 & $0.33-4.83$ \\
\hline Colon (C18-C19) & 2 & 5.37 & 0.37 & $0.04-1.34$ \\
\hline Rectum (C20-C21) & 0 & 3.27 & 0.0 & $0.00-1.13$ \\
\hline Liver (C22) & 1 & 0.84 & 1.19 & $0.02-6.65$ \\
\hline Gall bladder (C23-C24) & 0 & 0.44 & 0.0 & $0.00-8.38$ \\
\hline Pancreas (C25) & 0 & 1.92 & 0.0 & $0.00-1.92$ \\
\hline Respiratory system (C30-C39) & 1 & 11.5 & $0.09 *$ & $0.00-0.49$ \\
\hline Lung (C33-C34, C39) & 1 & 10.0 & $0.10 *$ & $0.00-0.56$ \\
\hline Bone and cartilage (C40-C41) & 0 & 0.72 & 0.0 & $0.00-5.12$ \\
\hline Skin (C43-C44) & 8 & 32.9 & $0.24 *$ & $0.10-0.48$ \\
\hline Melanoma (C43) & 2 & 8.10 & $0.25^{*}$ & $0.03-0.89$ \\
\hline Nonmelanoma (C44) & 6 & 24.8 & $0.24 *$ & $0.09-0.53$ \\
\hline Mesothelioma and soft tissue (C45-C49) & 3 & 1.59 & 1.58 & $0.32-4.60$ \\
\hline Breast (C50) & 3 & 18.6 & $0.16^{*}$ & $0.03-0.47$ \\
\hline Female genital organs (C51-C58) & 5 & 10.6 & 0.47 & $0.15-1.10$ \\
\hline Cervix (C53) & 0 & 4.79 & $0.0 *$ & $0.00-0.77$ \\
\hline Uterus (C54-C55, C58) & 2 & 2.49 & 0.80 & $0.09-2.90$ \\
\hline Ovary (C56-C574) & 3 & 2.87 & 1.04 & $0.21-3.05$ \\
\hline Male genital organs (C60-C63) & 14 & 8.64 & 1.62 & $0.89-2.72$ \\
\hline Prostate (C61) & 0 & 3.57 & 0.0 & $0.00-1.03$ \\
\hline Testis (C62) & 14 & 4.88 & $2.87^{*}$ & $1.57-4.82$ \\
\hline Urinary tract (C64-C68) & 5 & 6.77 & 0.74 & $0.24-1.72$ \\
\hline Kidney (C64) & 0 & 2.29 & 0.0 & $0.00-1.61$ \\
\hline Pelvis and ureter (C65-C66) & 1 & 0.42 & 2.36 & $0.03-13.1$ \\
\hline Bladder (C67) & 4 & 3.99 & 1.00 & $0.27-2.57$ \\
\hline Eye, brain, CNS (C69-C72) & 5 & 9.06 & 0.55 & $0.18-1.29$ \\
\hline Eye (C69) & 1 & 0.54 & 1.85 & $0.02-10.3$ \\
\hline Brain (C71, C751-C753) & 3 & 5.86 & 0.51 & $0.10-1.49$ \\
\hline Medulla, cranial nerves, and unspecified (C72) & 1 & 1.23 & 0.81 & $0.01-4.52$ \\
\hline Endocrine organs (C73-C74) & 0 & 1.54 & 0.0 & $0.00-2.40$ \\
\hline Other and poorly specified sites (C76-C80) & 3 & 2.43 & 1.24 & $0.25-3.61$ \\
\hline All solid tumors (C00-C80) & 55 & 121 & $0.45^{*}$ & $0.34-0.59$ \\
\hline All lymphomas and leukemia (C81-C96) & 58 & 10.6 & $5.50 *$ & $4.17-7.11$ \\
\hline Hodgkin lymphoma (C81) & 1 & 1.86 & 0.54 & $0.01-3.00$ \\
\hline Non-Hodgkin lymphoma (C82-C85, C883-C889) & 2 & 3.62 & 0.55 & $0.06-2.00$ \\
\hline Myeloma (C90, C880-C882) & 0 & 0.86 & 0.0 & $0.00-4.29$ \\
\hline \multicolumn{5}{|l|}{ Leukemia (C91-C96) } \\
\hline Lymphoid leukemia (C91) & 30 & 2.31 & $13.0 *$ & $8.74-18.5$ \\
\hline Myeloid leukemia (C92) & 19 & 1.61 & $11.8 *$ & $7.11-18.5$ \\
\hline Monocytoid leukemia C93) & 1 & 0.05 & 21.9 & $0.20-122$ \\
\hline Other leukemias (C94-C95) & 5 & 0.22 & $23.2^{*}$ & $7.48-54.2$ \\
\hline
\end{tabular}

$\mathrm{Cl}$, confidence interval; $\mathrm{CNS}$, central nervous system; ICD, International Classification of Diseases, 10th revision.

*Standardized incidence ratios (SIRs) significantly different from 1. 
Table 3. Standardized incidence ratios and observed and expected numbers of all malignancies ${ }^{\mathrm{a}}$ according to sex and type of constitutional cytogenetic abnormalities

\begin{tabular}{|c|c|c|c|c|}
\hline & Observed (n) & Expected $(n)$ & SIR & $95 \% \mathrm{Cl}$ \\
\hline \multicolumn{5}{|l|}{ Sex } \\
\hline \multicolumn{5}{|l|}{ All malignancies } \\
\hline Males & 61 & 60.9 & 1.00 & $0.77-1.29$ \\
\hline Females & 52 & 72.8 & 0.71 & $0.53-0.94$ \\
\hline \multicolumn{5}{|c|}{ Solid tumors (ICD-10 codes C00-C80) } \\
\hline Males & 33 & 53.5 & 0.62 & $0.42-0.87$ \\
\hline Males & 28 & 6.47 & 4.33 & $2.88-6.26$ \\
\hline Females & 30 & 4.09 & 7.34 & $4.95-10.5$ \\
\hline \multicolumn{5}{|l|}{ Constitutional karyotype } \\
\hline \multicolumn{5}{|l|}{ All malignancies } \\
\hline Standard trisomy 21 & 50 & 110 & 0.45 & $0.34-0.60$ \\
\hline Robertsonian translocations & 1 & 4.32 & 0.23 & $0.00-1.29$ \\
\hline Mosaicism & 4 & 6.34 & 0.63 & $0.17-1.62$ \\
\hline \multicolumn{5}{|c|}{ Lymphomas and leukemias (ICD-10 codes C81-C96) } \\
\hline Standard trisomy 21 & 54 & 9.68 & 5.58 & $4.19-7.28$ \\
\hline Robertsonian translocations & 1 & 0.40 & 2.47 & $0.03-13.8$ \\
\hline Mosaicism & 3 & 0.47 & 6.45 & $1.30-18.8$ \\
\hline
\end{tabular}

$\mathrm{CI}$, confidence interval; ICD, International Classification of Diseases, 10th Revision; SIR, standardized incidence ratio.

aMalignancies were analyzed combined and analyzed separately for solid tumors and leukemias.

germ-cell tumor $(n=1)$. The nine seminomas were diagnosed in a narrow age range of 33-41 years.

Females had a lower risk for solid tumors and a higher risk of leukemia than males (Table 3). The sex difference for solid tumor risk was attributable entirely to testicular cancer in males.

The SIR of solid tumors significantly decreased after 40 years of age (Table 4) and was lowest among persons 50 years or older (SIR 0.27; 95\% CI 0.16-0.43). Cancer was diagnosed in 46 children younger than 15 years of age, including 44 with acute leukemias $(96 \%)$, one infant with unilateral retinoblastoma, and one 9-year-old boy with Hodgkin lymphoma. The number of solid tumors among persons between 15 and 30 years of age was close to the expected number (SIR 1.23; 95\% CI $0.59-2.26$ ). The malignancies in this age group were dominated by germ-cell tumors ( 6 of 10 solid tumors).

The risk of leukemia was very high in children younger than 5 years of age, with an SIR of 27 for acute lymphoblastic leukemia (ALL) and 114 for acute myeloid leukemia (Table 5). The elevated risk of leukemia persisted until 30 years of age but with a higher risk for ALL than for acute myeloid leukemia. Three cases of acute leukemia were diagnosed after 30 years of age (versus the 2.0 cases expected).

The lifetime cumulative rates of leukemia at 5, 10,30, and 60 years of age among those with Down syndrome and the general population were $1.9,2.0,2.5$, and $2.9 \%$ vs. $0.04,0.06,0.11$, and $0.32 \%$, respectively. The corresponding cumulative rates of solid tumors at 30 and 60 years of age were 0.6 and $5.0 \%$ for those with Down syndrome versus 0.6 and $11.3 \%$ for the general population.

\section{DISCUSSION}

This cohort study of more than 3,500 persons with cytogenetically confirmed Down syndrome provides more precise estimates of the Down syndrome-associated cancer risk than previous studies, especially for adults. This includes better estimates of the increased risk of leukemia among children and young adults, and of testicular cancer among young adults, but also of the markedly decreased risk of several solid tumors.

Compared with a previous study of a subgroup of the same cohort $^{5}$ the person-years at risk increased from 48,453 to 89,571 , the person-years at risk from those above 40 years of age increased from 6,991 to 17,086, and the number of expected cancers increased from 50 to 134 .

The risk and types of cancers that occur in people with Down syndrome are strongly influenced by age. This is also true in the general population, but the pattern of cancer sites is very different in people with Down syndrome. At younger ages the overall risk is high because of the much higher risk of leukemias, but in the adult population, the risk is much lower because of the significantly decreased occurrence of solid tumors in older 
Table 4. Standardized incidence ratios and observed and expected numbers of solid tumors in 5-year age groups

\begin{tabular}{lcccc} 
Age group (years) & Observed $(\boldsymbol{n})$ & Expected $(\boldsymbol{n})$ & SIR & 95\% CI \\
\hline $0-4$ & 1 & 1.2 & 0.85 & $0.01-4.73$ \\
\hline $5-9$ & 0 & 0.7 & 0.00 & $0.00-5.33$ \\
$10-14$ & 0 & 0.7 & 0.00 & $0.00-5.41$ \\
$15-19$ & 4 & 1.3 & 3.08 & $0.83-7.89$ \\
\hline $20-24$ & 1 & 2.5 & 0.40 & $0.01-2.22$ \\
\hline $25-29$ & 5 & 4.4 & 1.15 & $0.37-2.68$ \\
$30-34$ & 5 & 6.7 & 0.74 & $0.24-1.74$ \\
\hline $35-39$ & 7 & 9.6 & 0.73 & $0.29-1.50$ \\
\hline $40-44$ & 6 & 13.6 & 0.44 & $0.16-0.96$ \\
\hline $45-49$ & 9 & 17.7 & 0.51 & $0.23-1.96$ \\
\hline $50-54$ & 6 & 19.7 & 0.31 & $0.11-0.66$ \\
\hline $55-59$ & 5 & 18.8 & 0.27 & $0.09-0.62$ \\
$\geq 60$ & 6 & 24.2 & 0.25 & $0.09-0.54$ \\
\hline Total & 55 & 120.9 & 0.45 & $0.34-0.59$ \\
\hline
\end{tabular}

$\mathrm{Cl}$, confidence interval; SIR, standardized incidence ratio.

Table 5. Standardized incidence ratios and observed and expected numbers of acute lymphoblastic and myeloid leukemia according to age

\begin{tabular}{|c|c|c|c|c|}
\hline Age group & Observed $^{\mathrm{a}}(n)$ & Expected $(n)$ & SIR & $95 \% \mathrm{Cl}$ \\
\hline \multicolumn{5}{|c|}{ Acute lymphoblastic leukemia (ICD-10 code C91) } \\
\hline 0 & 0 & 0.07 & 0 & - \\
\hline 1 & 1 & 0.12 & 8.2 & $0.1-46$ \\
\hline 2 & 5 & 0.12 & 42 & $13-97$ \\
\hline 3 & 4 & 0.12 & 33 & $9-84$ \\
\hline 4 & 5 & 0.12 & 40 & $13-94$ \\
\hline $5-9$ & 5 & 0.35 & 14 & $5-33$ \\
\hline $10-19$ & 5 & 0.32 & 16 & $5-36$ \\
\hline $20-29$ & 3 & 0.11 & 27 & $5-78$ \\
\hline$\geq 30$ & 2 & 0.97 & 2.0 & $0.2-7.5$ \\
\hline Total & 30 & 2.3 & 13 & $8.7-19$ \\
\hline \multicolumn{5}{|c|}{ Acute myeloid leukemia (ICD-10 codes C92, C93) } \\
\hline 0 & 2 & 0.02 & 132 & $15-476$ \\
\hline 1 & 5 & 0.03 & 188 & $60-439$ \\
\hline 2 & 7 & 0.03 & 267 & $107-554$ \\
\hline 3 & 2 & 0.03 & 76 & $8.5-273$ \\
\hline 4 & 0 & 0.03 & 0 & $0-137$ \\
\hline $5-9$ & 1 & 0.05 & 19 & $0.2-104$ \\
\hline $10-19$ & 0 & 0.16 & 0 & $0-23$ \\
\hline $20-29$ & 2 & 0.21 & 9.6 & $1.1-35$ \\
\hline$\geq 30$ & 1 & 1.11 & 0.9 & $0-5.0$ \\
\hline Total & 20 & 1.66 & 12.0 & 7.1-18 \\
\hline
\end{tabular}

$\mathrm{Cl}$, confidence interval; ICD, International Classification of Diseases, 10th Revision; $S I R$, standardized incidence ratio.

aFive patients with unclassified leukemia were excluded.

persons with Down syndrome. The overall cancer risk in people with Down syndrome is thus very dependent of the ages of participants in the cohort studied.
The pattern of cancer among children with Down syndrome is unique: more than $95 \%$ is acute leukemia. A case of retinoblastoma was the only nonhematologic tumor identified among children younger than 15 years of age in this study, confirming the paucity of embryonic tumors such as neuroblastoma, Wilms tumor ${ }^{11}$ and medulloblastoma. ${ }^{12}$

The risk of leukemia is very high among children with Down syndrome younger than 5 years of age, with an SIR of 27 for ALL and 114 for acute myeloid leukemia. The risk for leukemia, especially ALL, remains elevated until 30 years of age. The high risk of acute leukemia in young children with Down syndrome is unexplained, although multiple genes on chromosome 21 might be involved. ${ }^{13}$ It was recently shown that trisomy 21 leads to overexpression of HMGN1, which may promote B-lineage ALL by suppressing trimethylation of lysine 27 of histone $\mathrm{H} 3 .{ }^{14}$

The risk of all major groups of malignant solid tumors was decreased with the exception of testicular cancer. The risk of solid tumors was significantly reduced for men and women over 40 years of age; among the oldest age groups the cancer incidence was only $25 \%$ of that seen in the general population. Accelerated aging-for example, in the brain, ${ }^{15}$ hematopoietic cells ${ }^{16}$ and skin $^{17}$-in persons with Down syndrome might suggest an increased incidence of cancer, but the opposite was observed. The risk of therapy-related cancer is also decreased in persons with Down syndrome. ${ }^{3}$ The increased rate of apoptosis in cells with trisomy $21^{18}$ might mean that cell death is a more common response to DNA damage, thus reducing the risk of cancer. ${ }^{16}$

In contrast to other solid tumors, testicular tumors occurred three times more often than expected in men with Down syndrome, similar to the three- to fivefold increased risk of testicular cancer found in other studies. ${ }^{6,719-21}$ Testicular microlithiasis (asymptomatic calcification in the seminiferous tubules) and cryptorchidism (undescended testes), which both occur with increased frequency in Down syndrome and are associated 
with an increased risk of testicular cancer, ${ }^{22-24}$ might contribute to the increased incidence of testicular cancer. However, cryptorchidism alone cannot explain the increased risk since it is observed in less than $20 \%$ of testicular tumors among persons with Down syndrome. ${ }^{25}$ Acquired gain of chromosome 21 material occurs in most cases of seminoma, ${ }^{26}$ and chromosome 21 gene dosage may play a direct pathogenetic role in men with Down syndrome.

We observed an SIR of 1.0 for ovarian cancer, as was the case in the study from Finland. ${ }^{7}$ Other studies found a nonsignificant increase in the occurrence of ovarian cancers ${ }^{19,20}$ or decreased mortality from ovarian cancer among women with Down syndrome. ${ }^{6}$ We conclude that the risk of ovarian cancer is probably comparable to that in the general population.

Health behaviors associated with increased risk of cancer (e.g., smoking and sun exposure) might be less common in persons with Down syndrome compared with the general population. Some smoking-related cancers, such as lung cancer, were decreased to only $10 \%$ of expected, but the risk of other smoking-related cancers, such as stomach and bladder tumors, were not decreased in our cohort. The absence of cervical cancer might be related to decreased sexual activity - most women with Down syndrome are nulliparous ${ }^{27}$ despite being fertile.

Many adult men and women with Down syndrome are overweight and have low physical activity, ${ }^{28,29}$ but the increased risk of cancers of the breast, uterus, colon, intestine, liver, gallbladder, and kidney associated with high body mass index in the general population ${ }^{30}$ seems to be counterbalanced by protective factors in Down syndrome.

Nulliparity and obesity are associated with breast cancer in older women, ${ }^{31}$ but, despite both factors being present in the vast majority of women with Down syndrome, ${ }^{27,28}$ the occurrence of breast cancer is only $10 \%$ of the expected. Early menopause is more common in Down syndrome and might contribute to a reduced risk of breast cancer. ${ }^{32}$ The three cases of breast cancer in women with Down syndrome all occurred at relatively young ages $(31,47$, and 55 years), which may indicate less influence from lifestyle factors. We do not have any information on familial genetic predisposition to breast cancer in the cohort.

Chromosome 21 contains more than 200 genes, and several of these seem to be involved in carcinogenesis. ${ }^{16}$ Data from a mouse model of Down syndrome provide evidence for a tumor repressor effect of the chromosome 21 orthologous gene Ets $2 .^{33}$ Based on studies of mouse and human cells, the gene DYRK1A on chromosome 21 may possess both tumor-suppressor and leukemogenic properties. ${ }^{34}$

The reduced risk of solid tumors and benign vascular tumors in Down syndrome ${ }^{35}$ may be explained by endogenous antiangiogenetic regulators derived from genes on chromosome 21. Endostatin encoded by the COL18A1 gene at $21 \mathrm{q} 22.3$ is a potent angiogenesis inhibitor, and the serum concentration of endostatin is significantly higher in Down syndrome. ${ }^{36}$ Another chromosome 21-derived protein encoded by DSCR1 suppresses vascular endothelial growth factor-mediated angiogenesis and may also be involved in protection against solid tumors. ${ }^{37,38}$

This study has several strengths. It is based on a large unselected population of persons with Down syndrome, with a comparison with cancer rates in the sex- and agematched general Danish population from which the Down syndrome cohort was drawn. The large number of persons with Down syndrome and years of observation allow for precise estimates of the incidence of cancer. Use of the Danish Cytogenetic Registry means that ascertainment of persons with Down syndrome diagnosed since 1961 is likely to be complete. In addition, the use of these data allows analysis of the cancer risk by karyotype (standard trisomy 21, Robertsonian translocation, or mosaicism). The cohort data were linked to the Danish Cancer Registry, a database that is believed to be complete and to have a high degree of accuracy regarding type of tumor and ascertainment.

The study also has several limitations. The findings we observed could be due to cancer being less commonly diagnosed among persons with Down syndrome, rather than decreased incidence. The health-care system in Denmark is public and paid for by taxes, so lack of access is unlikely to explain the lower incidence of cancer. It is possible, however, that persons with Down syndrome might be less likely to report symptoms or to participate in cancer screening programs; thus, cancer might be diagnosed later. ${ }^{39}$ However, the finding of lower mortality from solid tumors among people with Down syndrome in other studies makes this explanation less likely. ${ }^{6}$ Another limitation is that information on cancer risk factors (e.g., tobacco use and sexual activity) was not available. Finally, the study was conducted in Denmark, which has a rather homogeneous Northern European population and might not be generalizable to other populations.

People with Down syndrome pose a paradox with accelerated aging but also a lower incidence of solid tumors compared with the age-matched general population. Better understanding of the decreased risk for most solid tumors among people with Down syndrome may lead to altered screening strategies for this group and may be helpful in identifying new methods for cancer prevention and therapy for the general population.

\section{ACKNOWLEDGMENTS}

The authors thank Jan Hansen from the Danish Cytogenetic Registry for data preparation and data manager Andrea Meersohn, Danish Cancer Society Research Centre, Copenhagen, Denmark, for data analyses.

The findings and conclusions in this report are those of the authors and do not necessarily represent the official position of the Centers for Disease Control and Prevention/Agency for Toxic Substances and Disease Registry.

\section{DISCLOSURE}

The authors declare no conflict of interest. 


\section{REFERENCES}

1. de Graaf G, Buckley F, Skotko BG. Estimates of the live births, natural losses, and elective terminations with Down syndrome in the United States. Am J Med Genet A 2015;167A:756-767.

2. Roizen NJ, Patterson D. Down's syndrome. Lancet 2003;361:1281-1289.

3. Hasle H. Pattern of malignant disorders in individuals with Down's syndrome. Lancet Oncol 2001;2:429-436.

4. Zhu JL, Hasle H, Correa A, et al. Survival among people with Down syndrome: a nationwide population-based study in Denmark. Genet Med 2013;15:64-69.

5. Hasle H, Clemmensen IH, Mikkelsen M. Risks of leukaemia and solid tumours in individuals with Down's syndrome. Lancet 2000;355:165-169.

6. Yang Q, Rasmussen SA, Friedman JM. Mortality associated with Down's syndrome in the USA from 1983 to 1997: a population-based study. Lancet 2002;359:1019-1025.

7. Patja K, Pukkala E, Sund R, livanainen M, Kaski M. Cancer incidence of persons with Down syndrome in Finland: a population-based study. Int J Cancer 2006;118:1769-1772.

8. Sullivan SG, Hussain R, Glasson EJ, Bittles AH. The profile and incidence of cancer in Down syndrome. J Intellect Disabil Res 2007;51(Pt 3):228-231.

9. Hasle H, Olsen JH, Nielsen J, Hansen J, Friedrich U, Tommerup N. Occurrence of cancer in women with Turner syndrome. Br J Cancer 1996;73:1156-1159.

10. Storm HH, Michelsen EV, Clemmensen IH, Pihl J. The Danish Cancer Registryhistory, content, quality and use. Dan Med Bull 1997;44:535-539.

11. Satgé D, Sasco AJ, Day S, Culine S. A lower risk of dying from urological cancer in Down syndrome: clue for cancer protecting genes on chromosome 21. Urol Int 2009;82:296-300.

12. Satgé $D$, Stiller $C A$, Rutkowski $S$, et al. A very rare cancer in Down syndrome: medulloblastoma. Epidemiological data from 13 countries. J Neurooncol 2013;112:107-114.

13. Maloney KW, Taub JW, Ravindranath Y, Roberts I, Vyas P. Down syndrome preleukemia and leukemia. Pediatr Clin North Am 2015;62:121-137.

14. Lane AA, Chapuy B, Lin CY, et al. Triplication of a 21 q22 region contributes to $B$ cell transformation through HMGN1 overexpression and loss of histone $\mathrm{H3}$ Lys27 trimethylation. Nat Genet 2014;46:618-623.

15. Beacher F, Daly E, Simmons A, et al. Brain anatomy and ageing in non-demented adults with Down's syndrome: an in vivo MRI study. Psychol Med 2010;40: 611-619.

16. Nižetić $D$, Groet J. Tumorigenesis in Down's syndrome: big lessons from a small chromosome. Nat Rev Cancer 2012;12:721-732.

17. Brugge KL, Grove GL, Clopton P, Grove MJ, Piacquadio DJ. Evidence for accelerated skin wrinkling among developmentally delayed individuals with Down's syndrome. Mech Ageing Dev 1993;70:213-225.

18. Rueda N, Flórez J, Martínez-Cué C. Apoptosis in Down's syndrome: lessons from studies of human and mouse models. Apoptosis 2013;18:121-134.

19. Boker LK, Merrick J. Cancer incidence in persons with Down syndrome in Israel. Downs Syndr Res Pract 2002;8:31-36.

20. Hermon C, Alberman E, Beral V, Swerdlow AJ. Mortality and cancer incidence in persons with Down's syndrome, their parents and siblings. Ann Hum Genet 2001;65(Pt 2):167-176.
21. Hill DA, Gridley G, Cnattingius S, et al. Mortality and cancer incidence among individuals with Down syndrome. Arch Intern Med 2003;163:705-711.

22. Vachon L, Fareau GE, Wilson MG, Chan LS. Testicular microlithiasis in patients with Down syndrome. J Pediatr 2006;149:233-236.

23. Pettersson A, Richiardi L, Nordenskjold A, Kaijser M, Akre O. Age at surgery for undescended testis and risk of testicular cancer. N Engl J Med 2007;356: 1835-1841.

24. Mercer ES, Broecker B, Smith EA, Kirsch AJ, Scherz HC, A Massad C. Urological manifestations of Down syndrome. J Urol 2004;171:1250-1253.

25. Miki M, Ohtake N, Hasumi M, Ohi M, Moriyama S. Seminoma associated with bilateral cryptorchidism in Down's syndrome: a case report. Int J Urol 1999:6:377-380.

26. Ottesen AM, Kirchhoff M, Rajpert De-Meyts E, et al. Detection of chromosomal aberrations in seminomatous germ cell tumours using comparative genomic hybridization. Genes Chromosomes Cancer 1997;20:412-418.

27. Zhu JL, Obel C, Hasle H, Rasmussen SA, Li J, Olsen J. Social conditions for people with Down syndrome: a register-based cohort study in Denmark. Am J Med Genet A 2014;164A:36-41.

28. Bell AJ, Bhate MS. Prevalence of overweight and obesity in Down's syndrome and other mentally handicapped adults living in the community. $J$ Intellect Disabil Res 1992;36(Pt 4):359-364.

29. Hsieh K, Rimmer JH, Heller T. Obesity and associated factors in adults with intellectual disability. J Intellect Disabil Res 2014;58:851-863.

30. Bhaskaran K, Douglas I, Forbes H, dos-Santos-Silva I, Leon DA, Smeeth L. Bodymass index and risk of 22 specific cancers: a population-based cohort study of $5 \cdot 24$ million UK adults. Lancet 2014;384:755-765.

31. Opdahl S, Alsaker MD, Janszky I, Romundstad PR, Vatten LJ. Joint effects of nulliparity and other breast cancer risk factors. Br J Cancer 2011;105:731-736.

32. Schupf N, Zigman W, Kapell D, Lee JH, Kline J, Levin B. Early menopause in women with Down's syndrome. J Intellect Disabil Res 1997;41(Pt 3): 264-267

33. Sussan TE, Yang A, Li F, Ostrowski MC, Reeves RH. Trisomy represses Apc(Min)-mediated tumours in mouse models of Down's syndrome. Nature 2008;451:73-75.

34. Birger $Y$, Izraeli S. DYRK1A in Down syndrome: an oncogene or tumor suppressor? J Clin Invest 2012;122:807-810.

35. Greene AK, Kim S, Rogers GF, Fishman SJ, Olsen BR, Mulliken JB. Risk of vascular anomalies with Down syndrome. Pediatrics 2008;121:e135-e140.

36. Zorick TS, Mustacchi Z, Bando SY, et al. High serum endostatin levels in Down syndrome: implications for improved treatment and prevention of solid tumours. Eur J Hum Genet 2001;9:811-814.

37. Baek KH, Zaslavsky A, Lynch RC, et al. Down's syndrome suppression of tumour growth and the role of the calcineurin inhibitor DSCR1. Nature 2009;459: 1126-1130.

38. Shin J, Lee JC, Baek KH. A single extra copy of Dscr1 improves survival of mice developing spontaneous lung tumors through suppression of tumor angiogenesis. Cancer Lett 2014;342:70-81.

39. Sullivan SG, Glasson EJ, Hussain R, et al. Breast cancer and the uptake of mammography screening services by women with intellectual disabilities. Prev Med 2003;37:507-512. 